\title{
Bipolar Patients' Quality of Life in Mixed States: A Preliminary Qualitative Study
}

\author{
Gitte Lee Mortensen $^{\mathrm{a}}$ Maj Vinberg ${ }^{\mathrm{b}}$ Steen Lee Mortensen ${ }^{\mathrm{a}}$ \\ Martin Balslev Jørgensen ${ }^{\mathrm{b}}$ Jonas Eberhard ${ }^{\mathrm{c}-\mathrm{e}}$ \\ ${ }^{a}$ AnthroConsult, Aarhus, ${ }^{b}$ Psychiatric Centre Copenhagen, Rigshospitalet, and ${ }^{\mathrm{C} B i p o l a r}$ Disorder, H. Lundbeck A/S, \\ Copenhagen, Denmark; ${ }^{\mathrm{d} C l i n i c a l}$ Sciences, Lund University, Lund, Sweden; ${ }^{\mathrm{E}}$ Institute of Psychiatry, Psychology and \\ Neuroscience (loPPN) at the Maudsley, King's College London, London, UK
}

\author{
Key Words \\ Bipolar disease - Mixed states · Mixed episodes . \\ Quality of life · Functioning · Qualitative research . \\ Mania with depressive symptoms · Dysphoric mania
}

for knowledge about this particularly severe expression of bipolar disorder. These results should be confirmed in a larger sample of patients with varying socioeconomic status.

(c) 2015 S. Karger AG, Basel

\section{Introduction}

Kraepelin [1] was the first to describe mixed states as 'states that do not exactly correspond either to manic excitement or to depression, but represent a mixture of morbid symptoms of both forms of manic-depressive insanity'. Kraepelin described the following six variants of mixed states: depression with flight of ideas, excited depression, depressive-anxious mania, inhibited mania, unproductive mania, and manic stupor. Mixed states are, in other words, clinical states in which symptoms of depression and mania combine and are characterized by the simultaneous presence of both depressive and manic symptoms [2]. Prevalence estimation for DSM-IV-TR and/or ICD-10 mixed episodes is approximately $20 \%$ of bipolar mood episodes but varies according to the diagnostic method [3-5].

Mixed states represent a complex syndrome, and the clinical heterogeneity within mixed states confuses the clinical presentation of bipolar disorder (BD), with the risk of misdiagnoses and maltreatment [5]. Bipolar patients with mixed states have been shown to have more psychiatric comorbidity, poorer treatment response, in-

\begin{tabular}{|c|c|}
\hline KARGER 125 & $\begin{array}{l}\text { (c) } 2015 \text { S. Karger AG, Basel } \\
0254-4962 / 15 / 0483-0192 \$ 39.50 / 0\end{array}$ \\
\hline $\begin{array}{l}\text { E-Mail karger@karger.com } \\
\text { www.karger.com/psp }\end{array}$ & $\begin{array}{l}\text { This is an Open Access article licensed under the terms of the } \\
\text { Creative Commons Attribution-NonCommercial 3.0 Un- } \\
\text { ported license (CC BY-NC) (www.karger.com/OA-license), } \\
\text { applicable to the online version of the article only. Distribu- } \\
\text { tion permitted for non-commercial purposes only. }\end{array}$ \\
\hline
\end{tabular}

Gitte Lee Mortensen, MSc

Owner and Senior Researcher

AnthroConsult

Fynsgade 24, DK-8000 Aarhus C (Denmark)

E-Mailglm@anthroconsult.dk 
creased relapse rate, decreased functional level, and higher risk of suicide [6-11]. Overall, mixed states are associated with a poorer prognosis and an aggravated longterm course of disease.

Clinical under-diagnosis of mixed states has led to changes in the revision of the diagnostic manual DSM-V, adding a new specifier 'with mixed features' that can be applied to bipolar I, bipolar II, BD not elsewhere defined, and major depressive disorder [12]. Changing the criteria is also discussed in the upcoming revision of ICD-11 in which a set of clear diagnostic criteria and exhaustive subtypes for mixed affective episodes are suggested $[13,14]$. There has been extensive discussion of how many symptoms from the opposite pole must be present nearly every day during 4 days of hypomanic, 1 week of manic or 2 weeks of depressive symptoms, respectively [15].

Symptom ratings alone are inadequate to comprehensively measure outcome in BD. Health-related quality of life (QoL) may be used as an additional construct $[16,17]$. QoL includes the patients' self-assessed emotional, social and physical well-being and ability to function in carrying out their ordinary tasks of living. Previous research has shown that euthymic BD patients are capable of providing valid self-assessments of their QoL $[18,19]$. Using participatory research methods, a disorder-specific measure of QoL (QoL.BD) was recently developed [20-23]. Still, no scale exists assessing patient experiences with mixed states, specifically. Some studies have demonstrated the usefulness of in-depth interviews with BD patients to increase the understanding of how the disorder is perceived and managed [24, 25].

There is a lack of clinical studies assessing bipolar patients' subjective experience with mixed states. The present study aimed to produce in-depth knowledge from a qualitative examination of remitted bipolar I patients' experiences with mixed states. Health-related QoL is embedded in sociocultural values and disease perceptions. Focusing on the social context of individual disease experiences, medical anthropology may provide novel insights into the QoL of patients suffering from $\mathrm{BD}$. We thus examined QoL related to mixed states using an anthropological approach.

\section{Materials and Methods}

Medical anthropology is a subfield of social anthropology that examines health-related issues in their sociocultural context. Many contributors to modern medical anthropology had their primary training in medicine, psychology or psychiatry such as Robert Levy and Arthur Kleinman [26-28].

Quality of Life in Mixed States of Bipolar Disorder

\section{Patients}

In-depth individual interviews were carried out with 6 patients diagnosed with bipolar I who experienced mixed states. An equal number of men and women were included (by M.V.) to examine possible gender differences. The patients' bipolar diagnoses were verified according to ICD-10 using the Schedules for Clinical Assessment in Neuropsychiatry (SCAN) [29]. All patients were included from The Copenhagen Affective Clinic, Psychiatric Centre Copenhagen, Denmark from May to September 2013. The Clinic is a specialized outpatient clinic for $\mathrm{BD}$. The psychiatrists follow the patients with evidence-based pharmacological treatment and regular appointments depending on their clinical status and needs. Thus, patients were included by their psychiatrist, who both clinically and through structured interviewing had diagnosed a mixed episode. When coming in to the clinic for their regular appointments, eligible patients received oral and written information about the study. Eligible patients acknowledged having experienced mixed states and were considered able and fit to participate in an interview by the consulting psychiatrist. At the time of the interviews, the patients were in remission. The participants' anonymity was safeguarded throughout. All gave their informed consent, with the possibility of opting out at any time, and the study did not require Danish ethics committee approval.

\section{Qualitative Interviews}

A literature study was carried out regarding patients' perceptions of BD and mixed states. MEDLINE, Embase and PsycINFO were searched using the key words 'bipolar'/'bipolar I disorder'/ 'manic depressive', or 'mixed features'/'mixed episodes'/'mixed state'/'mixed affective episodes' in combination with 'quality of life', 'perception', and 'patient experience', yielding a total of 2,147 studies published within a 10-year span. Limiting the literature study to publications from 2010 to 2013, and focusing on relevant articles about QoL in adults, the number was reduced to 138 studies. The literature study formed the basis of the design of a semi-structured interview guide beginning with questions on the participants' naming of their disease, their disease history, reaction to the BD diagnosis and perceived causes of disease. The participants then described their current state, typical disease fluctuations and experiences with treatment. Questions went on to focus on the participants' experiences with mixed states and their impact on QoL and functioning. The interviews were carried out in Danish by G.L.M., a trained qualitative interviewer. A standard iterative process was applied in which the interview guide was gradually modified (online suppl. file; www.karger.com/doi/10.1159/000381479).

\section{Data Analysis}

The interviews were transcribed verbatim and analysed using a discourse theoretical approach [30]. Following this, the participants' statements were seen as an expression as well as an ongoing construction of the meaning and personal impact of having BD with mixed states. This approach is a means to analyse a variety of statements such that clusters of meaning are generated; it involves an analysis of the terminology used to speak about the subject and the ways in which it is related to other issues. Firstly, the data were coded into the topics that were raised during the interviews. Secondly, the most important themes within each topic were identified. Finally, the frequency of and connections between topics and themes were analysed. This generated a pattern of the relative meaning that the different topics and themes had for the partici- 
pants, i.e. the patients' most significant experiences with mixed states. All methodological and analytical steps were discussed among the anthropologist authors, including the impact of interviewer/interviewee interaction. Disagreements were solved using Spradley's analytical resolution process of qualitative data [31]. The translation of the results from Danish into English was carried out by G.L.M. after the analysis and approved by all authors. The final manuscript was copy edited by a native English-speaking scholar (see Acknowledgements).

\section{Results}

\section{Participant Characteristics}

As described in table 1, 3 of the participants were employed and/or studying; 1 participant was a disability pensioner, and 2 were on sick leave. Their age and conjugal status varied. The participants had been diagnosed with BD 1-19 years before the interviews. In hindsight, all participants said they had experienced subthreshold BD symptoms since their teens, with abnormal mood fluctuations and depressive and/or hypomanic tendencies; 2 had received treatment for depression. Still, up until the time of diagnosis, the participants had studied, worked and had a social and love life, and some had children: 'People knew I was different but even so, I was part of society and I could adapt myself (34-year-old woman). Most explained that their mood episodes had gradually become more severe, more concomitant with symptoms from the other pole, and remittent periods became shorter. As a result, the $\mathrm{BD}$ diagnosis came as no surprise, although 2 of the participants (male 2 and female 1) still needed time to accept it.

The number of years living with $\mathrm{BD}$ had a large impact on coping. The participants said they gradually came to know their disease, its warning signals and means of somewhat coping with symptoms and mood fluctuations. The majority had received psycho-education and psychological counselling. Most had tried several classes of medicine such as anti-psychotics, anti-depressants, mood stabilizers, anti-epileptics, and tranquillisers. Some had received electro-shock therapy. With the exception of the most recently diagnosed participant, all believed they had arrived at an optimal individual treatment combination at the time of the interviews.

\section{Participants' Histories of Mixed States}

The participants had varying experiences with mixed states. For instance, 1 male who was diagnosed 17 years before said that his very first episode was mixed. He had since felt in a permanent subclinical mixed state and found it difficult to distinguish individual states; to him, it was mostly a question of pathological degree. Another man, diagnosed with BD 5 years previously, started experiencing mixed states a couple of years later, and 1 woman diagnosed 4 years before described the course of her disease as increasingly 'rapid cycling', with at least 4 mixed episodes per year now; 2 had their first experiences with severe mixed states within the past year. Finally, 1 had been diagnosed with $\mathrm{BD}$ for 9 years and had experienced mixed states almost from the start, with the latest severe episode half a year ago (table 1).

All participants with recent mixed states were slowly remitting at the time of the interview. They described the residual symptoms as prolonged and that they still felt vulnerable, dumb and sensitive to stress. The woman with a rapid cycling course of disease described every mixed episode as a setback, never fully allowing inter-episodic recovery. All participants said their larger mood fluctuations were currently suppressed by medication with the 'top and bottom having been cut off ( 49 year-old woman), but that the threat of a new full-scale episode was imminent. If not intervened against rapidly, and sometimes even despite this, a new mixed episode might evolve with a strength beyond the participants' control and taking several months from which to recover (Appendix: Patient Quote 1).

\section{Experiences with Being in Mixed States}

All participants said that mixed states were worse than any other state. They described mixed states as an intense synchronicity of depressed and accelerated thoughts, physical unrest (expressed in extensive walking or dancing, for instance) and exhaustion. Mixed states often started with insomnia; some would get numerous ideas of projects or social gatherings, but with no energy or confidence to carry through. Cognitive difficulties included lack of concentration and memory or speech impairment and pressure speech. Parents said their mixed states involved feelings of lacking proximity and emotion towards others, most painfully their children. Irritability, anger, social phobia, and panic attacks were also common. Two participants had experienced hallucinations; others mentioned over-stimulated senses and an urge to flee or isolate themselves. In particular, those living alone neglected themselves (stopped eating and bathing) and their homes. Most participants had experienced both rapidly shifting moods (minute by minute or hour by hour) and coinciding conflicting moods and urges: 'It tears you apart in every direction' (39-year-old male; Appendix: Patient Quotes 2). 
Table 1. Participant characteristics

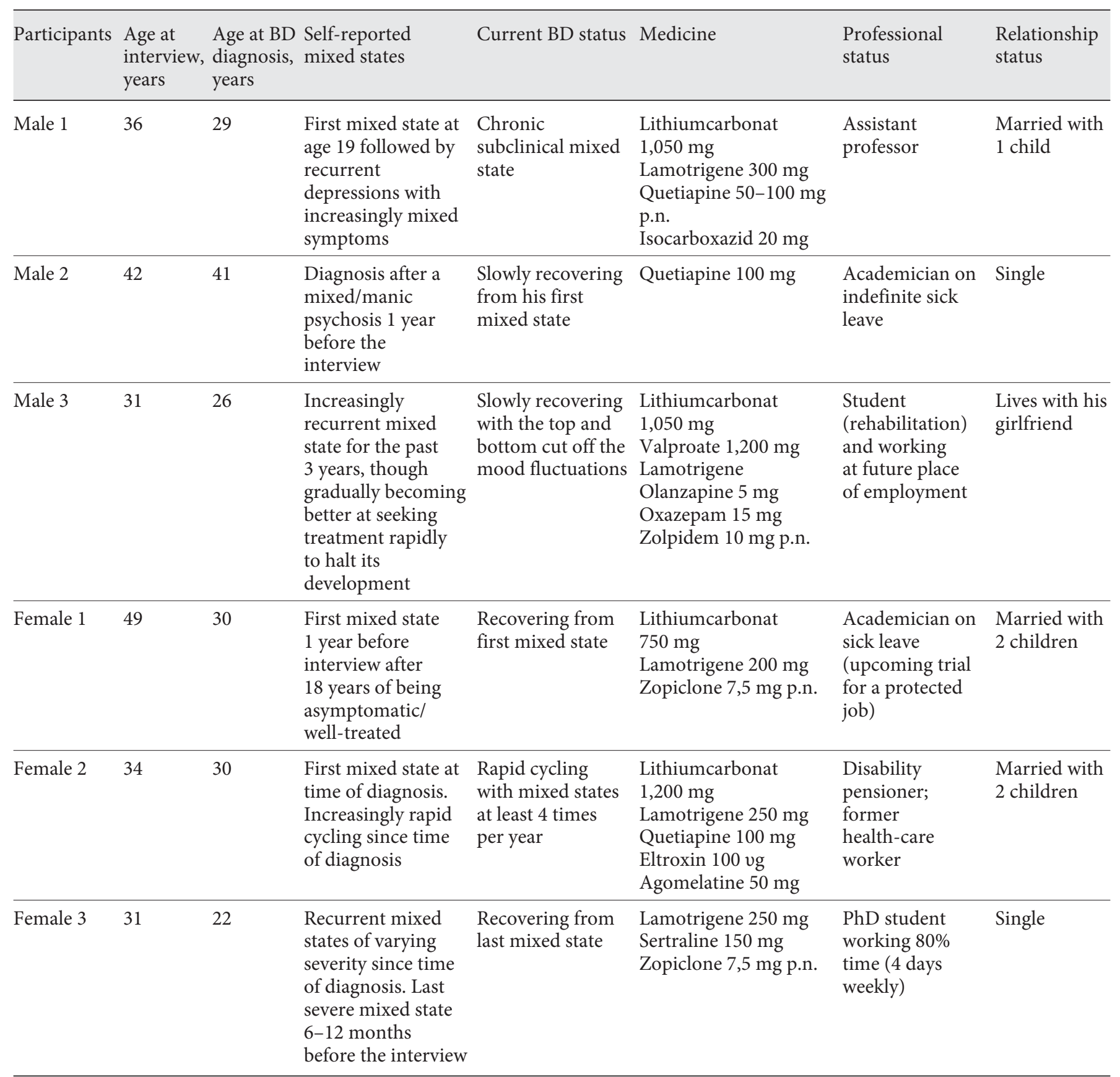

p.n. $=$ Per necessary

\section{QoL and Functioning in BD Mixed States}

The interviews enabled an analytical distinction between the participants' symptoms in mixed states (described above) and the ways in which mixed states affected their QoL and functioning in everyday life in the domains most important to them, namely their sense of self (identity), their family, love and social lives, their working capability, and their well-being with respect to comorbidity and side effects of medication. In practice, these domains were intertwined. For instance, a 34-year- 
Fig. 1. The impact of mixed states on significant areas of functioning in $\mathrm{BD}$ patients.

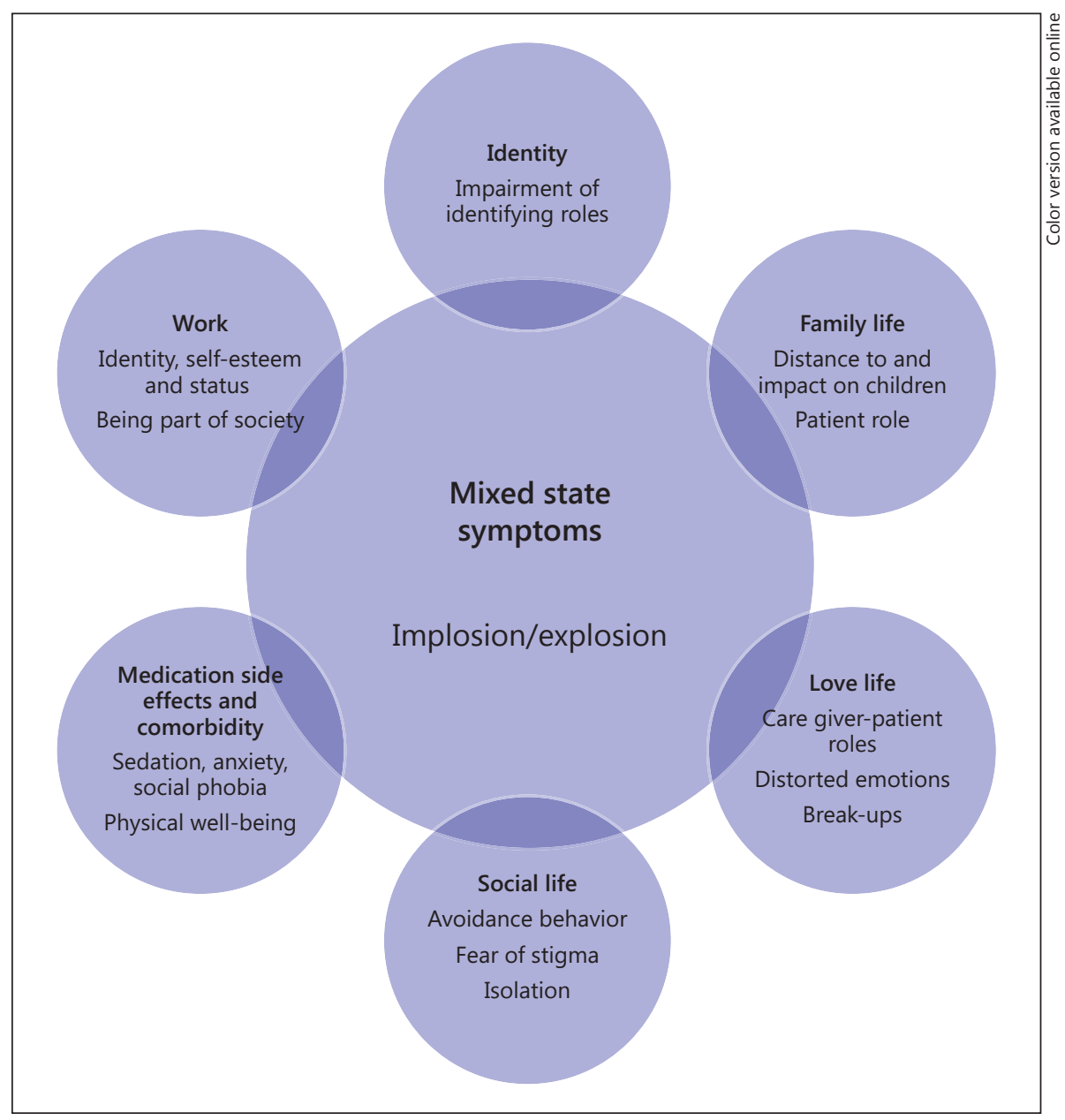

old woman described how increased medication made her feel sedated; this created a painful feeling of distance from her children, which sometimes led to self-loathing and suicidal ideations. The participants stated that it was during mixed states that their QoL in all important domains was at its lowest and their functioning most impaired (fig. 1).

\section{Impact of Mixed States on Identity and Self-Esteem}

In contrast to somatic illnesses that you may have, several participants felt that mental disorders are often seen by others as something you are. You are a 'manic depressive'. To them, all (had) identified closely with their work and 2 of the women, especially, with their motherhood (e.g. being a scholar or mother). Their functioning in both of these roles was particularly impaired during mixed states. The participants' self-esteem was at its lowest during mixed states, including feelings of guilt, hopelessness, not being lovable, respectable, or capable of fulfilling any important role in life. As this was a state where 'dark thoughts get a lot of energy' (49-year-old woman), more participants had experienced suicidal ideations during mixed states: 'All my suicide attempts have been during mixed episodes. During a depression, I may like the thought of dying but I don't have the energy to even think about how to execute it. In mixed states, I have the initiative to examine ways to do it and try. There are actually loads on Wikipedia about how to commit suicide' (31-year-old woman).

\section{Impact of Mixed States on Comorbidity and \\ Medication Side Effects}

Overall, BD and its treatment are associated with mental and physical comorbidity; mixed states are related to increased psychiatric comorbidity. To 4 participants, social phobia, anxiety and panic attacks were intrinsic features of their mixed states. They mostly considered side effects of medication such as trembling, fatigue 
and sedation as inevitable trade-offs, but 2 of the women found it difficult to accept weight gain. Side effects would increase with heightened levels of medication during mixed states.

\section{Impact of Mixed States on Family Life}

During mixed states, the participants felt they could hardly cope with themselves, much less with others. Unsurprisingly, this mainly affected relations with close relatives. For instance, 2 parents, or their partner and children, would leave for a summerhouse during bad days, and 1 participant had a room in the house 'to put the nutter into' to spare herself and her children, in particular, from contact during her mixed states (34-year-old woman). The parents were aware that their children were very attentive to their disease states and might get scared and worried - 1 even described his 3-year-old daughter as a 'differential diagnostician' (36-year-old male). The impacts of mixed states on children led parents to feel guilty and inadequate. Being a 'bad mother' was particularly worrying to the women. During mixed states, parents were reliant on their partners to take charge. Partners of patients with higher educational attainment appeared more supportive than the partner of the retired health care worker. Parents had abstained from acting on their suicidal ideations out of consideration for their families, while 2 participants had several suicide attempts when single.

\section{Impact of Mixed States on Love Life}

To the parents, their couple relations tended to be somewhat characterized as a patient-carer relation. They felt that mixed states put additional strain on their relationship - with 'carers' taking added charge of the 'patient' and household, for instance, while at the same time being a main target for anger and irritability. A 42-year-old homosexual man felt he had lost the love of his life due to his last mixed episode (Appendix: Patient Quote 3).

Later, this participant became pathologically obsessed with another man. Also, 1 of the married participants had, uncharacteristically, fallen in love with another patient during admittance to hospital with a mixed episode. With 1 exception, the participants' felt their love lives were much affected by BD and mixed states, in particular.

\section{Impact of Mixed States on Social Life}

All participants said that they tried to avoid social contact during mixed states. They needed to isolate themselves, but some also worried that their relations with friends and relatives might otherwise suffer irrepa- rable damage because of their erratic behaviour. Consequently, most friends and relatives did not fully comprehend the disease, as they did not see the participants at their worst. While this sometimes made the participants feel lonely, they considered this the best way to safeguard their social relations. One participant had indeed made numerous 'social disasters' during mixed/manic states, both at work, out on the town and among everyone he knew (Appendix: Patient Quotes 4).

In order to prevent triggering episodes and to stay as 'mood-neutral' as possible, the participants said they mostly tried to lead lives with rather strict routines: getting their sleep, eating regularly and avoiding stimuli such as coffee, alcohol and excessive sports. Some described this as a necessary but restrictive precaution that reduced their social QoL: 'That's the consequence of being well treated; you lose all the fun too. My optimal stability has come with the price of my social life. You are being cut out of society and, in a way, so is your family too' (34-yearold woman).

The important social aspects of $\mathrm{BD}$ was also reflected in the participants' preferred naming of the disease, namely 'manic depression' rather than BD. They felt that the former concept better encompassed their experiences with the simultaneity of contradictory symptoms in the disease, but also they considered this concept to be more familiar to others and thus improving social understanding.

\section{Impact of Mixed States on Working Capability}

The participants expressed that being able to hold down a job or uphold study was central to their selfesteem and feeling of being part of society. To the 3 participants working or studying, this was sometimes difficult even during subsyndromal mixed states due to reduced cognitive functioning. When possible, they would then avoid contact with others and preferred working in seclusion and undertaking less demanding tasks. Their academic professions allowed for some flexibility, including irregular working hours. If by necessity they had disclosed their BD diagnosis at their work place, and while they knew they were sometimes being 'handled' by colleagues, it was relieving to be met with consideration. The 2 scholars who were on sick leave hoped to return to work at some point, even if in protected job positions.

Overall, participants with higher educational attainment appeared to have better means of arranging everyday life in a manner flexible enough to encompass the disease. Some said that in their fields being a bit eccentric 
was socially acceptable and that academic work had been an important outlet for their hypomanic enterprises. In contrast, the participant formerly employed in home care for the elderly was required to be punctual and consistent in attendance, which did not allow for fluctuations in her working ability - hence her retirement. She now felt 'cut out of society' and lacked the social recognition associated with work (34-year-old woman). Working capability was thus important to the participants' confidence, and its social aspects were central to their QoL.

In conclusion, the participants associated having a job, a family and a social life with social status, having recognized functions to fulfil and self-esteem. Mixed states had the potential to obstruct all of that. As one participant put it, they set off 'that horrible feeling of not being in the game' (42-year-old man). The symptoms of mixed states were a burden in themselves. The ways in which they affected participants' functioning in key domains of life added significantly to this burden. Finally, the participants' QoL was not only linked to disease severity but also to the social resources of the person and his/her network. Overall, because of the circumstances, participants with higher educational attainment appeared more capable of coping with the disease than the retired health care worker, whose employer and relatives had difficulties in coping with her disease.

\section{Discussion}

This study was based on in-depth interviews with 6 patients. As qualitative research aims for an analytical but not statistical generalization of the results, this limited number is not in itself invalid vis-a-vis qualitative analysis - the point having been to produce in-depth knowledge of patients' experiences rather than, for instance, quantifiable prevalence of symptoms. Nevertheless, the results should be confirmed in a larger group of participants, with more differing socioeconomic status and with data collection continuing until a point of saturation is reached. The present study carries a significant selection bias in that 5 of the 6 participants had higher educational attainment. Besides being mostly high functioning, the participants' descriptions of mixed states were told in remission, i.e. carrying a possible recall bias.

The definition of mixed states has been discussed over decades, and different traditions have influenced the DSM and ICD nomenclatures, with one emphasizing functioning, while the other would use a phenomenological approach focusing on symptoms (pers. commun. with A. Bertelsen). Our study underlines that the relationship between symptoms and their impact on functioning is highly contextual. On the one hand, it depends on the sociocultural structure, including its health care services for the mentally ill, while on the other hand, it is related to individual 'social capital', including status and network resources [32].

Context is a key factor. For instance, religion played no role in our participants' coping with BD. Our sample was too small for statistical generalization, however. This contrasts with study results from North America where the CREST team identified 12 basic domains of patients' QoL, namely physical, sleep, mood, cognition, leisure, social, spirituality, finance, household, self-esteem, independence, and identity, leading to the development of the QoL.BD scale [16, 20-23, 33, 34]. Also, as welfare state citizens, our participants received financial support when out of work, and their means of working or studying on reduced hours or re-educating on rehabilitation benefit were favourable. In Denmark, hospital treatment is free of charge, implying that the financial and dependency impacts of BD and mixed states were comparatively lower than they may be in other countries.

With this study, we have shown how mixed states may particularly affect the lives of BD patients in domains considered crucial to their QoL, namely their family, love and social lives, their physical well-being and working capability and, ultimately, their identity and sense of self. To our participants, the intense synchronicity of manic and depressive symptoms gave 'dark thoughts a lot of energy', and their feelings of worthlessness and suicidal ideations increased. Psychiatric symptoms intensified, necessitating increased medication, again leading to added side effects. All close relations were disrupted as role functions failed, and some engaged in socially stigmatising behaviour. Working and studying, things that usually strengthened self-esteem and social integration, became increasingly difficult or impossible. Mixed states were long and difficult to recover from and these were the states most severely affecting QoL and functioning.

To our participants, symptoms of mixed states and functioning were related in multiple ways to significant domains of their lives (fig. 1). Previous studies support the finding that each of these domains indeed affects QoL and functioning in $\mathrm{BD}$ patients as a whole. Others have also shown that relational factors such as social support, 
family and couple functioning may be stronger predictors of patients' functioning than clinical status as measured by symptomology $[21,35,36]$. Also, external stigma and internalized stigma have been shown to play a significant role in contributing to the poor QoL associated with $\mathrm{BD}$, a key issue being the merging between self and illness [3739]. Our study does indeed show that BD might be seen as an integral part of patients' identity. While some studies found that disease state did not impact on self-stigma $[39,40]$, we found that mixed states accentuated both kinds of stigma and had an additional negative impact on patients' QoL.

In our participants, mixed states particularly affected work functioning, leading to retirement or sick leave in some and to periods of absence or low performance in others. Working ability is a key aspect of social functioning. A recent meta-analysis supports the indication that impairment decreases as education increases, validating our finding that social status may impact on functioning [41]. Others have shown that remitted BD patients suffer from both social and functional impairment, including high levels of work impairment $[42,43]$.

A total of 4 of our participants mentioned anxiety and panic attacks as intrinsic features of their mixed states. It is well established that comorbidity, e.g. anxiety disorder, social phobia and substance abuse, are frequently seen in BD patients [44]. Anxiety, in particular, is known to worsen the symptoms, course and prognosis and is linked to higher rates of suicide and further reductions in QoL and social function $[45,46]$. Our participants' self-esteem was closely linked to functioning in the above-mentioned life domains, implying that this was particularly affected during mixed states. Altogether, mixed states significantly reduced QoL and functioning in BD patients [47].

Seen from a patient perspective, improving QoL is of key importance [47]. A comparative analysis of the main goals of BD treatment among psychiatrists and patients, respectively, showed that coping ability and QoL improvement were the two most important issues to patients [48]. We found that patients' social resources might also be considered in order to optimize their QoL: which role does the patient have in different contexts and which functions are considered important to his/her subjective QoL? Which means do patients and their surroundings have to support patients' functioning in key life domains? With an aim to adequately identify and treat mixed states, our findings highlight the need for better assessments and knowledge about this particularly severe expression and impact of $\mathrm{BD}$.

Quality of Life in Mixed States of Bipolar Disorder

\section{Appendix}

Patient Quote 1: On Being in a Mixed State

'It's like a tornado or a hurricane, an awful thing that comes and take you and you can't do anything. You're inside the tornado, and you scream because it's got you. It takes over your thoughts. The mixed state is when you get really insane, when you get admitted to hospital, when you're out of control' (34-year-old woman).

Patient Quotes 2: On the Synchronicity of Opposing Symptoms in Mixed States

'You read and you write and you prepare constantly for the class. But you're working at $0.1 \%$ of your capacity. All you're doing is like an empty machine: oil is gone, everything's gone and you're just burning... I totally imploded like a black hole in that period... and then I bounced back. I exploded instead, and it's much the same energy. All I can say is that I hate nothing more on this earth than mixed state. In a way, I'd much rather get undiluted depression' (42-year-old man).

'Your thoughts are over-accelerated, you can think everything at one time, analyse everything, but the background of the analysis is hell, catastrophe. The thoughts are so accelerated that your lines of thought break, they disintegrate while happening. At the same time, your body is extremely agitated and the depressive mood is best described with the concept 'phrenalgia', a pain of being. And as you think everything at once, you can't hold on to one thought, analyse it and move on. You're just immersed in this encompassing experience of pain... Imagine if you were a tiny balloon: a depression squeezes it [the participant shows his fist] while the mania opens it from within. The mixed state is defined by the paradox that you experience both at the same time' (36-year-old man).

\section{Patient Quote 3: On the Impact of Mixed States on}

Relationships

'I had a dream job and a dream relationship, and then, just sailing into depression and, more and more, into a mixed state... My moods, I became intolerable. It [the break-up] was because of instability, increasing depression, panic attacks and anxiety, just losing control, you know. With him very stable and able to sleep, and me insomniac, coffee non-stop, smoking non-stop, beer, and then in the end, not eating, getting an ulcer, getting angry and not appreciating what I had been given' (42-year-old man).

\section{Patient Quotes 4: On the Impact of Mixed States on Social}

Relations and Stigma

'All those kids [students] who saw me, going nuts, and all those professors and colleagues... I looked like a starved raving werewolf, you know, more and more eccentric clothing, really colourful, because I got this hyper sense of colour. I wouldn't shave or perhaps only half my face. Just looking like a barking lunatic. I was marching, dancing in graveyards, talking to people, anyone. I know the exposure was so incredibly spectacular. I was on the go for $24 \mathrm{~h}$ in all these arenas. When I walk down the street today, the panic and anxiety is usually about that. Are people recognizing me?' (42-year-old man).

'When I realise that I'm becoming Dr. Jekyll and Mr. Hyde that I am shifting towards the ugly side - I stay away. I'm so afraid of losing people, of their gaze, that they give "that look" conveying prejudice, most of all, but also lack of knowledge and fear' (34-yearold woman). 


\section{Acknowledgements}

The authors wish to thank the participating patients for sharing their experiences with BD and mixed states. We are also indebted to Aksel Bertelsen who took time to share some of his vast knowledge about $\mathrm{BD}$ and the development of the ICD and DSM nomenclatures with respect to mixed states/episodes. Finally, G.L.M. wishes to thank her dear friend, Emeritus Professor Michael Pugh, University of Bradford, for copy editing the final manuscript.

\section{Disclosure Statement}

AnthroConsult, owned by G.L.M., has received an unrestricted research grant from $\mathrm{H}$. Lundbeck $\mathrm{A} / \mathrm{S}$ to carry out the present study. M.V. has acted as consultant for Eli Lilly, H. Lundbeck A/S, AstraZeneca and Servier. M.B.J. has served on advisory boards for Eli Lilly and Astra Seneca. J.E. is senior medical advisor at H. Lundbeck A/S. S.L.M. has no conflicting interests.

\section{References}

1 Kraepelin E: Manic-Depressive Insanity and Paranoia. Edinburgh, Livingstone, 1921.

$\checkmark 2$ Goodwin FK, Jamison KR: Manic Depressive Illness, Bipolar Disorders and Recurrent Depression, ed 2. Oxford, Oxford University Press, chapt 2, 2007.

-3 Bertschy G, Gervasoni N, Favre S, Liberek C, Ragama-Pardos E, Aubry JM, Gex-Fabry M, Dayer A: Frequency of dysphoria and mixed states. Psychopathology 2008;41:187-193.

4 Vieta E, Morralla C: Prevalence of mixed mania using 3 definitions. J Affect Disord 2010; 125:61-73.

5 Azorin JM, Baraille L, Gérard S, Bertsch J, Reed C, Lukasiewicz M: Mixed states with predominant manic or depressive symptoms: baseline characteristics and 24-month outcomes of the EMBLEM cohort. J Affect Disord 2013;146:369-377.

-6 Baldessarini RJ, Salvatore P, Khalsa H-MK, Tohen M: Dissimilar morbidity following initial mania versus mixed-states in type-i bipolar disorder. J Affect Disord 2010;126:299_ 302.

7 Cassidy F, Yatham LN, Berk M, Grof P: Pure and mixed manic subtypes: a review of diagnostic classification and validation. Bipolar Disord 2008;10:131-143.

-8 Rosa AR, Reinares M, Franco C, Comes M, Torrent C, Sánchez-Moreno J, MartínezArán A, Salamero M, Kapczinski F, Vieta E: Clinical predictors of functional outcome of bipolar patients in remission. Bipolar Disord 2009;11:401-409.

9 Valentí M, Pacchiarotti I, Rosa AR, Bonnín CM, Popovic D, Nivoli AMA, Murru A, Grande I, Colom F, Vieta E: Bipolar mixed episodes and antidepressants: a cohort study of bipolar I disorder patients. Bipolar Disord 2011;13:145-154.

10 Martin-Carrasco M, Gonzalez-Pinto A, Galan JL, Ballesteros J, Maurino J, Vieta E: Number of prior episodes and the presence of depressive symptoms are associated with longer length of stay for patients with acute manic episodes. Ann Gen Psychiatry 2012;11:7.

11 Young AH, Eberhard J: Evaluating depressive symptoms in mania: a naturalistic study using a structured diagnostic tool, the DMS-5 'With Mixed Features' specifier M.I.N.I. module. Poster presentation 27th ECNP Congress, Berlin, October 2014.
12 American Psychiatric Association 2011: DSM-5 Development. Proposed Revision of Major Depressive Disorder. http://www. dsm5.org/ProposedRevisions/Pages/ proposedrevision.aspx? $\mathrm{rid}=44 \# 2011$.

13 World Health Organisation: The International Classification of Diseases, 11th Revision. Geneva, WHO, 2011. http://www.who.int/ classifications/icd/revision/information notes/en/index.html.

14 Østergaard SD, Bertelsen A, Nielsen J, Mors O, Petrides G: The association between psychotic mania, psychotic depression and mixed affective episodes among 14,529 patients with bipolar disorder. J Affect Disord 2012;147:44-50.

15 Swann AC, Lafer B, Perugi G, Frye MA, Bauer M, Bahk W-M, Scott J, Ha K, Suppes T: Bipolar mixed states: an international society for bipolar disorders task force report of symptom structure, course of illness, and diagnosis. Am J Psychiatry 2013;179:31-42.

16 Michalak EE, Murray G: Development of the QoL.BD: a disorder-specific scale to assess quality of life in bipolar disorder. Bipolar Disord 2010;12:727-740.

17 Murray G, Michalak EE: The quality of life construct in bipolar disorder research and practice: past, present, and possible futures. Bipolar Disord 2012;14:793-796.

18 Wallcraft J: Service users' perceptions of quality of life measurement in psychiatry. Adv Psychiatr Treat 2011;17:266-274.

19 Michalak EE, Yatham LN, Lam RW: Quality of life in bipolar disorder: a review of the literature. Health Qual Life Outcomes 2005;3:72.

20 Michalak EE: The Collaborative Research Team to study psychosocial issues in bipolar disorder (CREST.BD). Bipolar Disord 2010; 12(suppl 1):37.

-21 Michalak EE, Yatham LN, Kolesar S, Lam RW: Bipolar disorder and quality of life: a patient-centered perspective. Qual Life Res 2006; 15:25-37.

22 Murray G, Michalak EE: The quality of life in bipolar disorder (QoL.BD) scale: Development and psychometric properties. J Affect Disord 2010a;122(suppl 1):36-37.

23 Murray G, Michalak EE: Addressing the need for a disorder-specific quality of life scale for bipolar disorder: psychometric properties of the quality of life in bipolar disorder (QoL. BD). Bipolar Disord 2010b;12(suppl 1):40.
24 Moltu C, Stefansen J, Svisdahl M, Vesteth M: Negotiating the coresearcher mandate - service users' experiences of doing collaborative research on mental health. Disabil Rehabil 2012;34:1608-1616.

25 Moltu C, Stefansen J, Svisdahl M, Veseth M: How to enhance the quality of mental health research: service users' experiences of their potential contributions through collaborative methods. Am J of Psychiatr Rehabil 2013;16:1-21.

26 Good B, Fischer MMJ, Willen SS, Del Vecchio M-J (eds): A Reader in Medical Anthropology: Theoretical Trajectories, Emergent Realities. Malden, Wiley-Blackwell, 2010.

27 Janzen JM: The Social Fabric of Health. An Introduction to Medical Anthropology. New York, McGraw-Hill, 2002.

28 Hahn RA, Inhorn MC: Anthropology and Public Health: Bridging Differences in Culture and Society. Oxford, Oxford University Press, 2010

29 Wing JK, Babor T, Brugha T, Burke J, Cooper JE, Giel R, Jablenski A, Regier D, Sartorius N: SCAN (Schedules for Clinical Assessment in Neuropsychiatry). Arch Gen Psychiatry 1990; 47:589-593.

30 Winther Jørgensen M, Phillips L: Diskursanalyse som teori og metode (discourse analysis as a theory and method). Roskilde, Roskilde University Press, 1999.

31 Spradley JP: The Ethnographic Interview. New York, Holt, Rinehart \& Winston, 1979.

32 Bourdieu P: Outline of a Theory of Practice. Cambridge, Cambridge University Press, 1977.

33 Lee S, Lee D, Bahk W: A study of reliability and validity of the Korean version of the quality of life in bipolar disorder questionnaire. Eur Neuropsychopharmacol 2012;22(suppl 2):288289.

34 McBride S, Michalak E, Youngstrom E: Advancing bipolar disorders research via collaborative knowledge translation. Int Clin Psychopharmacol 2012;28(suppl A):69.

35 Crowe M, Inder M, Carlyle D, Wilson L, Whitehead L, Panckhurst A, O'Brien A, Joyce $P$ : Feeling out of control: a qualitative analysis of the impact of bipolar disorder. J Psychiatry Ment Health Nurs 2012;19:294-302.

36 Sheets ES, Miller IW: Predictors of relationship functioning for patients with bipolar disorder and their partners. J Fam Psychol 2012; 24:371-379. 
-37 Michalak E, Livingston JD, Hole R, Suto M, Hale S, Haddock C: 'It's something that I manage but it is not who I am': reflections on internalized stigma in individuals with bipolar disorder. Chronic Illness 2011;7: 209-224.

- 38 Guillaume S, Courtet P, Chabannes J-P, Meynard J-A, Moreau-Mallet V: Management, needs and expectations of patients suffering from bipolar I disorders (The ECHO study - France). Encephale 2011;37:332338.

39 Ustundag MF, Kesebir S: The relationship of internalized stigmatization in bipolar disorder with quality of life and treatment compliance. Bipolar Disord 2012;14(suppl 1:90.

40 Norman RMG, Windell D, Lynch J, Manchanda R, Norman RMG: Parsing the relationship of stigma and insight to psychological well-being in psychotic disorders. Schizophr Res 2011;133:3-7.
Mann-Wrobel MC, Carreno JT, Dickinson D: Meta-analysis of neuropsychological functioning in euthymic bipolar disorder: an update and investigation of moderator variables. Bipolar Disord 2011;13:334-342.

42 Michalak EE, Yatham LN, Maxwell V, Hale S, Lam RW: The impacts of bipolar disorder upon work functioning: a qualitative analysis. Bipolar Disord 2007;9:126-143.

43 Trak SN, Alisir BM, Karada H, Örsel S, Türkc $\mathrm{H}$ : Functioning in remission phase of bipolar disorder: a controlled study. Bipolar Disord 2012;14(suppl 1):131.

44 Toprak E, Karamustafalioglu O, Goksan Yavuz B, Bakim B, Ozer O: Anxiety disorder comorbidity in patients with bipolar disorder. Eur Neuropsychopharmacol 2011;21(suppl 3): 436-437.

45 Maina G, Rosso G, Aguglia A, Chiodelli DF, Bogetto F: Anxiety and bipolar disorders: epidemiological and clinical aspects. Ital J Psychopathol 2011;17:365-375.
6 Chang CT, Hsu Y-W, Lu R-B, Chang CT: Neuropsychological functions in bipolar-I and bipolar-II disorders comorbid with or without anxiety disorders. Int Clin Psychopharmacol 2011;26(suppl A):e8-e9.

47 Yatham LN, Kennedy SH, Parikh SV, Schaffer A, Beaulieu S, Alda M, O’Donovan C, MacQueen G, McIntyre RS, Sharma V, Ravindran A, Young LT, Milev R, Bond DJ, Frey FN, Goldstein BI, Lafer B, Birmaher B, Ha K, Nolen WA, Berk M: Canadian Network for Mood and Anxiety Treatments (CANMAT) and International Society for Bipolar Disorders (ISBD) collaborative update of CANMAT guidelines for the management of patients with bipolar disorder: update 2013. Bipolar Disord 2013;15:1-44.

48 Maczka G, Siwek M, Skalski M, Grabski B Dudek D: Patients' and doctors' attitudes towards bipolar disorder - do we share our beliefs? Psychiatr Pol 2009;43:301-312. 